\title{
EXPLORING THE ROLE OF UPDATED TECHNOLOGY IN UNIVERSITY ENGLISH LANGUAGE CLASSROOM
}

\author{
Asst. Prof. Dr. Sundus Aj. Kamil \\ UNIVERSITY OF BAGHDAD/COLLEGE OF EDUCATION FOR HUMAN SCIENCES-IBN-RUSHD \\ sundus_kamil@yahoo.com
}

\begin{abstract}
Technology nowadays has become the trend of every aspect of life and teaching is not away from the that fad. What Elbert Einstein indicates "It has become appallingly obvious that our technology has exceeded our humanity" ,has been sharply outlined. The adoption of updated technology represents an important advance in modern English language teaching methods. The use of technology in an English classroom is involved with a variety of technical gadgets like a variety of mobile phones, wireless phone, laptop, tablets, notebooks, pen drives, online dictionary in addition to social media such as Facebook, Orkut, and Google search. English classes have become a part of the novel trends. They encourage the English teachers to investigate the best appropriate one which optimizes the class for better learning English. The present term-paper is intended to shed the light on the role undertaken by up-to-date technology in optimizing English classrooms nowadays. The aim of this study is to identify the role updated technology in language classrooms undertake to nurture and support language learning. This research is a descriptive one where a sample of (90) second year students at the Department of English/ College of Education /IbnRushd /University of Baghdad are randomly chosen to respond to the questionnaire items which are adopted from a previous study to identify the role undertaken by updated technology in language classroom. The students' responses have been statistically analyzed and rejected positively the null hypothesis to capture the importance of updated technology in boosting language learning on the students' part.
\end{abstract}

Article Received: 18 October 2020, Revised: 3 November 2020, Accepted: 24 December 2020

\subsection{Introduction:}

Currently, students in all stages of learning characterize the generation grown with the modern technology. They have spent most of their times harnessing laptops, videogames, digital music players, cell phones, video cams and all the other digital toys and applications. Language classroom has been part of the new inventions. The way that hones English teacher look for the most fruitful one to turn his class into a proper environment for learning English.

It has been a great demand on English teacher's part to develop the up-to-date technology to learn English for the reason that it appeals to young generation students' minds. Since eyes and ears are essential senses for learning, the students can learn much better by developing these widgets.

\subsection{Theoretical Background: (Wang:2004)} indicates when language learners have desirable and real communication factors, they can develop their language skills using computers and every kind of technological equipment gives students the sense of freedom and encouragement. Learning a foreign language is a demanding process and students are always in need of being boosted and supported. The use of technology involves a lot of benefits in the classroom. (Ellis:1994) points out that creating challenging tasks and activities motivates the language learners.

With the aid of technology students can be more active, instigated and indulged in learning process. It is also necessary to positively try to enhance the effect of developing technology in language classroom to achieve the required results been prospected.

(Becker :2000) states that computers are considered as an important instructional instrument in language classes in which teachers have convenient access, are sufficiently prepared, and have some freedom in the curriculum. Computer technology is viewed by a lot of teachers as an effective means of delivering 
education of high quality. Moreover, linguists such as (Gençlter :2015) and Tomlison (2009) believe that computer-based activities provide learners with rapid information and appropriate materials.

They suppose that internet materials provide a motivation for further learning on learners' part. (Larsen-Freeman and Anderson :2011) as well support the standpoint indicates that technology provides teaching resources and brings learning experience to the learners' world.

Technology provides many authentic materials to learners and they can be highly incited in learning language world. Researchers as (Solanki and Shyamlee1:2012) and(Gilakjani :2017) stipulate the view that language teaching method has been changed because of technology. The researchers assert that the application of technology assists learners learn language on the basis of their interests.

It also satisfies both visual and auditory senses of the learners. (Lam and Lawrence :2002) and (Gilakjani :2017) suggest that technology assists learners in moderating their own learning process and they can have access to a great deal of information that their teachers cannot provide. Gilakjani and Sabouri (2014) assert that learners can have their own control on their own learning process through the use of up-to-date technology and have access to a variety of information the way that technology can promote and support their classroom activities, the matter which consequently facilitates and furnishes the teaching method adopted. As a result, language teachers should be knowledgeable with all these technologies in handling the four language skills, otherwise they will never be able to sustain with these technologies. As Bull and Ma (2001)indicate that technology supplies limitless resources to the learners of a certain language. Both Harmer (2007) and Gençlter (2015) accent that teachers should provoke learners developing the proper activities out of using computer technology to enhance their success in language learning. Harmer (2007) believes that using computer- based language activities can support cooperative learning among learners.

Technology has always played a significant role in teaching and learning environment. It is an indispensable part of the teachers' line through which teachers can facilitate the process of handling the information as far as language is concerned. Since technology has been involved with one's everyday life, it is proper to consider the idea of integrating technology into language syllabus and aim to ingrain technology into teaching for the learning process sake. Due to using technology, learners can master their own learning process and access so abundant information over which their teachers cannot control. Technology has even an influential impact on teaching methods developed by language teachers. According to( Bennett, Maton and Kervin:2008), developing learners' knowledge and skills applicable to computer technology feed parity of opportunity, whatever learners' background. Despite the fact that, learners have been born into a technologically rich world, they may not be veteran developers of technology .Moreover, only providing access to technology is insufficient. purposeful development of technology-based knowledge is necessary for all learners in order to upgrade their learning.

\subsection{Language Classroom Appropriate}

\section{Technological Gadgets}

To have your language classroom more technologically optimized, the following gadgets are to be developed among students according to www.fluentu.com;

\subsubsection{Memrise}

Memrise can be utilized as one of the best spaced repetition apps to acquire vocabulary out there that words presented by the app are those needed by your students mostly to review. With this application, students can perform multi functions as far as vocabulary is concerned. They can spell, speak, type and even translate from their mother tongue into the target language and vice versa. 
Memrise is algorithm zed in the sense that it can recognize and specify the words need to be repeated on student's part. On teacher's part, s/he might have a certain list of words for his/her class to know. They can upload the words to the program surfing into the Memrise website. Then to go to "Courses," which is on top of homepage where a page with a "Create A Course" button appear. Having it clicked on a series of steps will permit you to add the word list that your class can have an access to even when they are at home.

\subsubsection{FluentU}

FluentU is the place where most online favorable language learning videos are found by which, students can be immersed in real-world video clips such as movie trailers, music videos and vlogs. Moreover, technology can ensure that students get the most from every clip you put on. How is that ? every single word in the transcription is a portal to a deep investigation that translation, meaning, pronunciation, images, usage examples are all provided.

FluentU can also be utilized for exercises, illustrations discussions and other activities. For instance, if one wants to teach vocabulary within a particular field. One can find a video on various genres (economics, culinary, arts and so) by surfing and categorizing according to language level to examine appropriateness for the class. A video can be watched and learnt as a group.

Students can also use FluentU to study with outside of class, and create their own flashcard sets. Moreover, FluentU can pull content from videos across the program the way that students can learn vocabulary in context with clips from movie trailers, vlogs, cartoons and other real-life content provided with example content and quizzes that are epitomized by each student's unique needs.

"Assignments" feature can also used to assign students' homework, as well as navigate each student's progress through responding to quizzes provided. Actually, FluentU is customized to make things related to language learning less difficult and more fun for both teachers and students.

\subsubsection{Language Nut}

This program tackles upon the four language skills: listening, speaking, reading and writing. Students will have the opportunity to involve with the target language through songs, games and stories . For instance, students will be able to pair words with their corresponding images through a game of tic-tac-toe. Everything goes on in a smoothly user interface with fashionable graphics that students will enjoy it. Language Nut is beneficial because it navigates student activity. Students can have an access even when they are outside the classroom. Whether they listen to songs or stories, or play certain games, the software will automatically send their scores, basically to show how individual students are doing on certain aspects of the course. The matter which provides a feedback about the material given according to students' needs.

\subsection{4 i Translate Converse}

iTranslate Converse is an app for immediate translation that one can speak a word or an expression in a certain language and can receive the instant translation into the target language.

It's mainly used by travellers for instance, a traveller who lacks the words to express in the target language can optimize the app to manage the situation. This app can support learning language classrooms by motivating the students to translate certain expressions and to check by themselves through this app whether their translations are correct or not i.e. whether they manage themselves in the target language or not. Developing such an app in language classrooms will be fun and amusement on learners' part and beneficial on teacher's method of teaching.

\subsubsection{SMART Board}

Developing Smart Board technology in the classroom can nourish your curriculum by adapting a typical lesson and turning it into a fun, more collaborative one. Smart Boards ;the 
amazing technology not only supports what teachers teach, but it also supports what students learn. It supplies students with an enhanced visual learning experience. According to www.teachhub.com, it also provides the teachers with the opportunity to accommodate different learning styles. Visual learners can prospect the whiteboard, whereas tactile ones can activate the fun of learning through touching the board. The touchscreen option gives teachers the chance to run programs with finger's tap. This makes it not only easy to navigate for the teacher but for the students as well.

besides, by technology a student's learning experience is upgraded through viewing videos, charts and diagrams just right on the huge screen in front of them. The matter which facilitates a great deal their learning opportunities .

\subsubsection{BBC Languages}

BBC Languages is a website that provides lessons in major languages like Italian German ,French and Spanish. This site accommodates content assortment such as vocabulary exercises, grammar drills in addition to video tutorials and interactive dramas in a way to help students have their target language strengthened. This site provides interviews with transcripts, bulletins with subtitles and news reports delivered sluggishly for language learners .It proposes a great deal of resources for major languages to teachers to harness them in their classes like worksheets or interactive videos. In a nutshell, technology can bring wonders to language classes if it is properly handled. It can vividly facilitates the process of learning by making it more fun and intuition.

\subsection{Advantages of Tech-Oriented Language Instruction}

There are a lot of advantages of developing technology in language classroom for creating , practical, simple and more creative activities as indicated

by

www.newcollegegroup.com/blog/technology-

english-language-teaching.

\subsubsection{Motivation in learning}

Technology plays an essential role in everyday life for most of people and students are the ones who can handle it in their classes the way which asserts the use of technology in English language teaching and learning. Technology captivates and attracts both teachers and students. Boosting students to take part is perhaps the most important part of any lesson plan, integrating technology in an innovative way may renovate an overcast lecture into an engaging one.

Since much of language learning comes from practice outside of the classroom, inspiring students with ground-breaking ideas is significant as well. If a student has an interest in what is being taught, they are far more likely to pursue more information by themselves.

\subsubsection{Education Beyond Classroom}

Just by having a Wi-Fi code, accessing technology in education will greatly participate in its success. Moreover, this accounts both in and outside of the classroom. Learning materials are now not merely reading a textbook, it outspreads now to smartphones and tablets. Learners can teach themselves beyond the classroom, in real life situations by adapting technology in English language teaching and learning.

\subsubsection{Further Practice}

Students who are less acquainted with the technology used in the classroom, using it in lessons offers much-needed practice. Technology is set to take a front seat in learning, and in all life aspects . So students worth the opportunity to acquaint themselves with using different appliances in various ways, not just in developing language skills.

\subsubsection{Beyond Restrictions}

Technology is evidently not to be used in place of effective teaching only, but to be used in text-tospeech conversion, interactive tasks, and online tutorials which permit students to translate on-thego. Autonomous learning, with access to related teaching material for enhancement which means further practice and consequently more confidence to push perceived limitations. Students are encouraged to handle books beyond their current reading level.

\subsubsection{Providing context for the English language}


Practicing English outside a classroom provides exposure to English culture, and a real-life context regarding what they are learning. Opportunities to practice English in a real setting are far more freely available through news sites and social media, or join online forums. The matter which provides a variety of language use that is difficult to imitate in the classroom.

\subsubsection{Transforming Education}

It's obvious that not only classrooms benefit from the latest tools for learning but also teachers benefit from streamlined, effective teaching practices by integrating technology in the classroom. As indicated by

Nik Peachey http://www.scoop.it/t/nik-peachey in an interview, technology "has a huge potential to transform education on a global scale" and it's wholeheartedly approved.

\subsection{Disadvantages of Tech-Oriented Language Instruction}

The immersion of technology in education has been more pertinent as millennial and the gen $\mathrm{X}$, who are now in charge being teachers, become reliant on devices. In spite of the abundant modernizations and new notions the education technology (EdTech) revolution carried to the classroom, teachers can't over regard the downsides of using technology in the classroom.

According

https://brandongaille.com.Technology

in

education may draw certain shortcomings as follows:

\subsubsection{Sidetracking to students.}

Technology access can be just as a daily routine just like addicting as alcohol, drugs, or even gambling. In a survey in the United States, it has been shown that average person accesses their smartphone about 100 times a day. That act happens even if there are nil notifications for them to log in. Students may access other modules of the online experience instead of the learning experience. Only distinct limits and prospects to track can counter this matter in order that technology can offer a desirable learning opportunity.

\subsection{2 parting students from face-to-face interactions.}

Interacting with people online is a very different skill than vis-à-vis interaction. When people feel like they can be unidentified, they tend to miss the filter that they use over their words and manners. Some people even detach from consistent social interactions for the coziness of a screen, words, and emojis. For this reason technology should be used as a device in the classroom. It cannot be the only module of the learning procedure for students.

\subsubsection{Contributing to cheat.}

Technology permits easier communiqué among people and that is quite helpful. Yet, that simplicity of communication makes cheating more probable. That is in a mere group email broadcast one can share the responses to a test or quiz, mainly if the teacher is not in a monitor position and the students are freely interacting on the computer. One way to manage this issue is to deliver assignments which necessitate an individual insight. Encouraging thoughtful processing instead of mere memorization usually diminishes the need to cheat.

\subsubsection{Baffling students to use untrustworthy resources for learning}

There is a great deal material that one can find online nowadays. Yet, there is a lot of false and misleading data as well. Accordingly, students should learn how to handle a valuable information basis apart from what might be labeled as "false news." Judging a questionable content could place students at a disadvantage when it comes time to shape out a spot for themselves with the rest of society.

\subsubsection{Planning curriculum more difficult or expensive.}

Not all the teachers have the ability to employ the contemporary gadgets that have them better systematized nowadays. Learning how to handle a new apparatus can be just as laborious as proceeding to earn a certification in a field. Some institutions may not assist with the costs of these gadgets either, but suppose them to be in the classroom. 


\subsubsection{Interchanging the teacher}

With a program like $\mathrm{ABC}$ Mouse, students can communicate with a programmed online teacher as they accomplish learning lessons. That turns the teacher into a role of manager or observer. Teachers could never become outdated, but technology in the classroom has interchanged much of what they used to do in the past already.

\subsubsection{Violating privacy.}

Having students involved with advanced technology sets their privacy at-risk every day. Even though most apps and software have severe privacy procedures in place, there is no way to completely reduces the risks that are involved in this context.

\subsubsection{Straining for some students.}

Gazing at a computer screen, a smartphone screen, or a tablet screen can result in an eye strain. When this happens, the signs may include irritation of the eye, feelings of fatigue, and even blurred vision. It may also lead to a more severe condition that is called "Computer Vision Syndrome."

\subsubsection{Missing track of time.}

Students usually miss track of time when they are harnessing a device with a screen. This leads to lengthy periods of sitting, which could result in deadlock, obesity, and other undesirable matters. It can also interfere with sleep patterns. The matter which results in bad sleep habits which negatively affect student's learning experiences.

\subsubsection{0 limiting uses.}

Classroom technology is mostly confined to word processing needs or elementary research. The plentiful uses of modern technology are either not allowed or partially excluded, often for political or personal issues. That restricts the efficiency of technology and modifies the learning opportunities that students have in a negative way.

\subsubsection{Creating a dependence.}

Technology can offer access to a infinite amount of information, but it can gradually make a personal dependence upon that access. Having extensively used technology students might feel upset by the idea of picking up a real book to read. They might even resist going outside for vacation or to contribute in family activities.

\subsection{Tech-based Learning Enhancement}

Learning process according to https://elearningindustry.com can be optimized through certain methods. The following lines go through these methods and how they take language classrooms to another level.

\subsubsection{Adopting Effective Approach}

Different kinds of experiences lead to different brain structures as indicated by Dr. Bruce D. Berry, Baylor, The idea is to frame an approach where both competence and efficacy can be upgraded. This approach should be concentrating on all facets of online education: theory of learning, syllabus, teaching and learning experiences, technology, administration, and institutional philosophy to have a positive effect on the real experiences of learning.

\subsubsection{Supplementing Videos}

Because of the widely approval digital videos witness, integrating them into the e-Learning process would bring forward a multipurpose and convenient sparkle to education. Moreover, videos would lead to:

\subsubsection{Engaging Sensorial Experience}

Learners could hear and see what they are being taught and will practice them in an analogous way during daily interactions. Moreover, they greatly contribute in the learning process, mainly the multipart topics that require a high level of understanding.

\subsubsection{Going-to Resources}

The videos are one of the astounding go-to resources that can be viewed anytime and from anywhere. If students are online, then they can use their smartphones, tablets, and laptops.

\subsubsection{Improving Digital Proficiency}

Online learning can increase students' digital proficiency, and this is undoubtedly one of the most major expertise of the present century.

\subsubsection{Upgrading The Power of Communication}

Communication is the foundation to prosperous online education and, by time, this field has witnessed some conspicuous improvements. The courses should follow the potential of 
communication through channels of social media, student chat groups, e-mails, and more, giving students a means to communicate with their colearners and teachers as well.

\subsubsection{Implementing Virtual Reality (VR)}

The fairly new technology of Virtual Reality (VR) has taken over electronic classes in an implausible speed. The main idea behind VR in education depends on how the human brain works. The brain is normally capable of memorizing $10 \%$ of what students read, $20 \%$ of what they hear and nearly $90 \%$ of what is being achieved or inspired. According to elearningindustry.com

The ways that VR can be encompassed in online learning are:

\subsection{Special Education}

For physically impaired students, VR can function as a blessing in mask. They get to probe the whole world by their headset besides the fact that, this can cause a perfect impact on their learning process as well.

\subsection{Content Creation}

Nowadays, VR courses have been mostly concentrated on history and science courses, yet VR technology can be modified to any subject or topic, promising limitless possibilities.

\subsection{Field Trips}

By VR technology students can get to places that are physically unreachable or remote, giving them a sense of attendance to them. Theoretically, these classes are considered as a robust challenger against traditional classrooms.

\subsubsection{Having Flexible Lesson Plans}

Learning online, students can study at their own pace, yet the lesson plan might still be conventional. Instead of the traditional rules, courses need to discover malleable lesson plans manipulated according to students' specific needs. By doing this, students don't have to endeavor at one topic for hours but alternatively achieve with focused study time on problematic notions.

\subsubsection{Recruiting Competent and Skilled Teachers}

However, progressive or exclusive the eLearning system might be, it should always be supported by a team of experienced and skillful teachers who design courses according to the students' needs. Such a course basically includes orderly schedule, thoughtful curriculum and related elements that would make the learning process as all-in-one as it can be. Even when shifting to online education, the experienced teacher constitutes an essential requirement.

\subsubsection{Taking Result-Oriented Assessments}

Online courses mostly do lack result-oriented assessments, that's why a student who does not score well, they would have to repeat the course altogether and go through same curriculum and chances which would end up with similar scores, such a cycle can be ended with the aid of resultbased assessments. Result-oriented assessments have a major role to play. This mainly investigates the aspects where students fail to score and then delivers simple step-by-step learning programs followed by tests to help them do better.

\subsubsection{Budgeting To Turn Methods Into Action}

If an institution lacks the required finances for developing an exceptional online course then a good procedure would be to seek out help from dependable online lenders. The core of inventive eLearning system is not only based on the modules but the amount of money supposed to be spent on making it valuable. Therefore, when planning to build a successful online course, the above-mentioned practices are to be considered to make an apparent difference in the learning process.

1.7 Methodology: The research methodology of the present study is based on a questionnaire adapted from(www.ukessays.com , essays , .(Gay,1996) indicates that the use of the questionnaire has some certain benefits over other methods of data collection that are not available through other sources i.e. a questionnaire is much more efficient that it requires less time, it is less expensive, and permits collection of data from much larger sample. To explore the role of updated technology in language classroom. The questionnaire has been validated by giving the initial version of the questionnaire to a number of 
Jurors . The Jurors are among the teaching staff in the field of English Language Teaching and Linguistics in the Colleges of Arts, Education, and Languages / University of Baghdad. They have been requested to point out their remarks and suggestions about the appropriateness of the items of the questionnaire. According to their recommendations, the final version of the questionnaire is modified. To obtain a representative range of prospect on the role of technology in language classroom the subjects are appraised on their perceptiveness of technology usage and consequence within the language classrooms working on the questionnaire items [see App].The questionnaire has been given to (90) second year students at the Department of English/ College of Education/Ibn-Rushd for the academic year 2019-2020 after finishing the second semester of digital (distant) learning since the Google Classroom has been developed in Iraq due to Pandemic COVID19 lockdown procedures.. The questionnaire consists of a basic question and (10) items with five responses accompanying each;( 1-Totally Disagree; 2Strongly Disagree; 3-Agree; 4-Strongly Agree; and 5-Totally Agree) according to Likert Scale. Thus, each item requires students to encircle a number 1 through 5 with its equivalent qualitative value on scale. For example, the basic question in the questionnaire asks the student in concern ; What do you think might be the reasons that the Internet gadgets could facilitate English learning? Students in concern are then supplied with(10) items explain the reasons which make Internet technology simplifies and enhances language learning where (5) possible responses below each item as follows: ;( 1-Totally Disagree; 2Strongly Disagree; 3-Agree; 4-Strongly Agree; and 5-Totally Agree). After the questionnaire items been demonstrated and elucidated, the subjects are requested to complete the questionnaire to the best they can. Having the responses collected, the researcher has analyzed the data according to individual item response frequency. A small number of of students have encircled more than one response per question.
Subsequently, the inconsistent responses have been excepted from analysis. The responses have been analyzed statistically through the use of the weighted mean and weighted percentile of the subjects' responses to refute the null hypothesis and prove that updated technology positively contributes in enhancing and facilitating language learning and results come to capture the role played by technology in making language learning more fun besides simplifying interaction among students and eventually participates positively in supporting learners' autonomy.

Conclusions: There are certain conclusions drawn out of this study shown as follows:

1.In webpages navigation, the probabilities of unswervingly reading English and acquiring new vocabulary, grammatical patterns and sentence patterns, augmented.

2. The propinquity of the online instructing facilitates the process that a teacher can correct their mistakes rapidly.

3. The updated technology gadget can motivate learners for better language learning through the facilities provided within.

4. The updated online technology can create and nurture autonomous learners, have more fun and interest in what they surf as far as language learning is concerned.

5.The learners, through navigating webpages, could necessarily have more exposure to the target culture and real-life linguistic situations which eventually foster their communicative activities and skills.

\section{References}

[1] Becker, H. J. (2000). Findings from the teaching, learning, and computing survey: Is Larry Cuban right? Education Policy Analysis Archives, 8(51). doi: http://dx.doi.org/10.14507/epaa.v8n51.200 $\underline{0}$

[2] Bennett, S., Maton, K., \& Kervin, L. (2008). The 'digital natives' debate: A critical review of the evidence. British Journal of Educational Technology, 39(5), 
775-86. https://doi.org/10.1111/j.1467$\underline{\text { 8535.2007.00793.X }}$

[3] Bull, S., \& Ma, Y. (2001) Raising learner awareness of language learning strategies in situations of limited recourses.Interactive Learning Environments, 9(2), 171-200. doi: 10.1076/ilee.9.2.171.7439

[4] Ellis, R. (1994). The study of second language acquisition. Oxford: Oxford University Press.

[5] Gençlter, B. (2015). How does technology affect language learning process at an early age? Procedia - Social and Behavioral Sciences, 199(2015), 311 316.

doi:

10.1016/j.sbspro.2015.07.552Lam and Lawrence :2002

[6] Larsen- Freeman, D., \& Anderson, M. (2011). Techniques and principles in language teaching. Oxford: OUP

[7] Pourhossein Gilakjani, A. (2017). A review of the literature on the integration of technology into the learning and teaching of English language skills. International Journal of English Linguistics, 7(5), 95-106. doi:

[8] https://doi.org/10.5539/ijel.v7n5p95

[9] Pourhossein Gilakjani, A., \& Sabouri, N. B. (2014). Role of Iranian EFL teachers about using Pronunciation Power software in the instruction of English pronunciation. English Language Teaching, 7(1), 139148. doi:

[10] http://dx.doi.org/10.5539/elt.v7n1p139Gay ,1996

[11] Harmer, J. (2007). The practice of English language teaching. England: Pearson. www.worldcat.org/title/practice-ofenglishlanguage-teaching/oclc/149005881

[12] Solanki, D., \& Shyamlee1, M. P. (2012). Use of technology in English language teaching and learning: An analysis.2012International Conference on Language, Medias and Culture IPEDR vol. 33(2012)@(2012)IACSIT Press,
[13] Singapore. 150-156.

[14] Tomlinson, B. (2009). Materials development in language teaching. Cambridge: Cambridge University Press.

[15] Online Resources

[16] www.fluentu.com

[17] www.teachhub.com

[18] https://brandongaille.com.

[19] https://elearningindustry.com

[20] www.ukessays.com

[21] http://www.scoop.it/t/nik-peachey

\section{$\operatorname{Appendix}(\mathbf{A})$}

What do you think might be the reasons that the Internet Gadgets could facilitate English learning? (1-Totally Disagree; 2-Strongly Disagree; 3Agree; 4-Strongly Agree; and 5-Totally Agree)

1. The teacher interacted with students on the Internet so that I feel less pressured in class.

2. I can learn new vocabulary, sentence patterns, and grammar on the Internet.

3. Anonymous communication makes me less afraid of making mistakes in English chatting.

4.I could learn good English sentences through You-Tube ,Fluent U and Language Nut.

5. I don't need to speak English in front of my classmates. Instead, typing in front of the computer screen reduces my stress.

6. Learning English won't be that boring since I could find some intriguing English information on the Internet quickly.

7. I could improve my English response speed since online chatting in English requires instantly answering in English.

8. I could make key/pen pals in foreign countries and practice English writing.

9. I could often practice English since English is the common language on the Internet, developing my vocabulary through i Translate Converse and Google Translator.

10. I could freely practice English because I could build up my little virtual world on the computer screen through developing Smart Board through touchscreen options viewing videos, charts and diagrams. 